\title{
Compreensão literal e inferencial em crianças com Distúrbio Específico de Linguagem
}

\author{
Joyce Raquel Toba ${ }^{1}$
}

Toba JR. Compreensão literal e inferencial em crianças com distúrbio específico de linguagem [dissertação]. São Paulo: Faculdade de Medicina, Universidade de São Paulo; 2010. 90p.

O diagnóstico precoce das alterações de compreensão oral é imprescindível para a intervenção efetiva. Porém, avaliar a compreensão é uma tarefa difícil, pois estratégias compensatórias podem mascarar dificuldades. Dada a importância de instrumentos apropriados para a avaliação de habilidades receptivas, o estudo comparou crianças com Distúrbio Específico de Linguagem (DEL) com um Grupo Controle quanto à compreensão de discurso. Participaram do estudo 47 sujeitos, distribuídos em dois grupos: Pesquisa e Controle. No Grupo Pesquisa, havia 21 sujeitos com DEL entre 8:0 e 8:9 anos, frequentadores do Laboratório de Investigação Fonoaudiológica em Desenvolvimento da Linguagem e suas Alterações da Universidade de São Paulo. No Controle, 26 sujeitos com desenvolvimento normal de linguagem entre 7:10 e 8:11 anos, frequentadores de duas escolas públicas de São Paulo. Ambos os grupos responderam a perguntas literais e inferenciais sobre duas narrativas gravadas digitalmente. Os materiais e os procedimentos basearam-se nos critérios de Bishop e Adams (1992), Norbury e Bishop (2002). Havia três formas de resposta: espontânea, com incentivo e por múltipla escolha. Priorizou-se a primeira. Ausente a resposta, forneceu-se auxílio na forma de encorajamento ou de alternativas. Utilizou-se um sistema de três pontos para a análise quantitativa das respostas. As completamente corretas receberam dois pontos. As parcialmente corretas, um ponto. Já as ausentes ou totalmente incorretas, nenhum. Os erros foram classificados quanto à natureza em: (1) Alternativa Incorreta; (2) Falha de Compreensão Literal; (3) Inferência Errada; (4) Resposta Atípica I; (5) Resposta Atípica II e (6) Falha de Compreensão do Escopo da Pergunta. Foram observadas diferenças quantitativas e qualitativas entre os grupos. O teste não paramétrico de Wilcoxon revelou que o Grupo Pesquisa obteve pontuações estatisticamente mais baixas, tanto em compreensão literal como inferencial de discurso. Ambos os grupos produziram predominantemente respostas espontâneas. Porém, a Análise de Variância demonstrou que as crianças com DEL precisaram de alternativas com mais frequência. Essa análise também confirmou diferenças nos padrões de erro. A tipologia de erro predominante em ambos os grupos foi a Inferência Errada. Contudo, o Grupo Pesquisa cometeu os seguintes erros com mais frequência que o Controle: Alternativa Incorreta, Falha de Compreensão Literal e Resposta Atípica I. Por fim, o Modelo de Regressão de Poisson revelou que o desempenho do grupo com DEL esteve diretamente relacionado ao tempo de terapia e inversamente à idade. Em suma, as crianças com DEL apresentaram desempenho quantitativa e qualitativamente pior que os pares cronológicos na tarefa de compreensão de discurso. Tais resultados corroboram os achados descritos na literatura. Portanto, reforçam a necessidade de identificação precoce das dificuldades de compreensão de escolares com DEL.

Dissertação apresentada ao Programa de Pós-graduação em Ciências da Reabilitação da Faculdade de Medicina da Universidade de São Paulo - USP - São Paulo (SP), Brasil, para obtenção do título de Mestre em Ciências, sob orientação da Profa. Dra. Debora Maria Befi-Lopes.

(1) Mestre, Fonoaudióloga da Prefeitura de Jandira - Jandira (SP), Brasil.

Endereço para correspondência: Joyce Raquel Toba. R. Justino Alves Batista, 89/220, Osasco (SP), Brasil, CEP: 06126-120. E-mail: joyce.raquel@yahoo.com 